\title{
Dental Phobia
}

National Cancer Institute

\section{Source}

National Cancer Institute. Dental Phobia. NCI Thesaurus. Code C35140.

A persistent, irrational fear of treatment, whether preventative or therapeutic, by a dentist, coupled with compulsive desire to avoid any such situation. 